\title{
COLECCIÓN SIN PIEDAD. ASESINOS MÚLTIPLES 2 ASESINOS EN SERIE 1
}

\author{
Palabras preliminares de la autora
}

Prólogo del Dr. Vicente Garrido Genovés*

\section{GARCIA ROVERSI, SUSANA. (2011).}

GARCIA ROVERSI, SUSANA. (2014). COLECCIÓN SIN PIEDAD. Asesinos Múltiples 2 Asesinos en serie 1. Argentina, Buenos Aires: HS Grupo Editorial HS. 542 p. ISBN 978-987-26342-2-3

\section{RESEÑA}

\section{PALABRAS PRELIMINARES DE LA AUTORA}

Finalmente, he aquí la primera parte del volumen 2 de la "Colección Sin Piedad": Asesinos Múltiples 2. Asesinos seriales. Los motivos por los cuales es editado en dos partes, principalmente son dos: el primero, con el fin de evitar un libro difícil de manejar por el lector por su cantidad de páginas y el segundo para que el lector pueda tener mucha más información sobre estos asesinos

\footnotetext{
* Es profesor titular de la Universidad de Valencia, en materias relacionadas con la Psicología Criminal y la Pedagogía para la readaptación de los delincuentes. Doctor en Psicología y diplomado en Criminología, el Doctor Garrido es uno de los pioneros y de las autoridades más reconocidas en el ámbito de la criminología violenta. Ha sido consultor de Naciones Unidas para la prevención de la delincuencia en Latinoamérica, y un firme impulsor de los programas para tratar a jóvenes y adultos violentos, incluyendo agresores sexuales y delincuentes psicópatas, acerca de los cuales ha publicado numerosos artículos y libros. Actualmente dirige la implantación de un programa para delincuentes sexuales en ocho prisiones españolas. Entre sus últimos libros publicados figuran Principios de Criminología y Diccionario de Criminología. En 1998 colaboró con la Guardia Civil en la identificación y captura de Joaquín Ferrándiz, el asesino confeso de cinco mujeres de Castellón. Realizó su perfil criminal y posteriormente, ya en prisión, actuó como perito para los tribunales. Impulsor de la psicología criminal y de la pedagogía correccional en nuestro país, es autor de un importante trabajo científico y de divulgación en el ámbito de la criminología. Formó parte de la Comisión que se encargó de redactar la Nueva Ley de Responsabilidad Jurídica del Menor, aprobada en enero de 2000. El Ministerio de Justicia le ha concedido la Cruz de San Raimundo de Peñafort. Vicente Garrido colabora habitualmente en programas de radio y televisión, y escribe artículos de opinión y científicos en diversos medios, así como en revistas científicas nacionales e internacionales. Destacan entre sus publicaciones: Amores que matan, Contra la violencia, El psicópata, Los hijos tiranos: el síndrome del emperador, La mente criminal, El rastro del asesino: el perfil psicológico, entre otras.
}

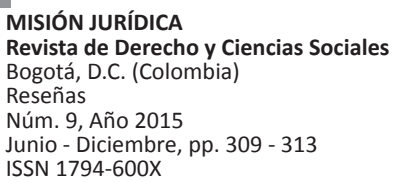


tan particulares, además de que ello permite un costo más accesible y la libertad de adquirirlos por separado o juntos, aunque ambos están correlacionados entre sí y con el volumen anterior.

El estudio y abordaje del tema de los asesinos seriales no es una tarea sencilla; por el contrario es realmente algo complicado y extenso, lo cual incidió, de forma determinante, en lo explicado en el párrafo anterior. Existe bastante literatura al respecto pero en su mayoría es en inglés, además de que algunas obras tratan la historia de algún/ nos asesino/s en particular -a los cuales me agrada denominar "los conocidos de siempre"- y mientras que otros autores profundizan en la Psicología y la Criminología alrededor del fenómeno de la serialidad criminal. Es por ello, además, que una cantidad importante de estos sujetos, como así también distintos aspectos y factores relativos al tema, son prácticamente desconocidos tanto en el ámbito de la Criminología, la Psicopatología Forense y el público en general.

Mi objetivo principal, como lo he explicado en el volumen anterior, es que esta Colección esté al alcance de todo tipo de público: que el lector, en forma concreta y concisa, con un lenguaje claro y sin tecnicismos -para el que desee ampliar determinados términos, los va a encontrar en las notas al pie o en la bibliografía citada- compruebe por sí que, en estos casos especialmente, el fenómeno de la serialidad criminal, estuvieron presentes en la sociedad desde tiempos muy remotos y constan en los anales del crimen internacional, en unos países más que en otros, en unas épocas más que en otras.

Pero, invariablemente, la mayoría de las veces en que se aborda este tema, siempre surgen los mismos nombres y se ha escrito muchísimo sobre ciertos asesinos en serie, mientras que otros sólo son conocidos a nivel local nacional -algunos $\mathrm{y}$ no todos- $\mathrm{y}$ del resto ni siquiera se conoce $\mathrm{su}$ existencia, nombre y/o accionar criminal.

En estas palabras previas, no voy me voy a adelantar sobre esto, puesto que lo desarrollo en extenso a lo largo de este segundo volumen, pero de algo estoy segura: muchos quedarán sorprendidos del desarrollo e investigación exhaustivos -aunque dinámico y versátil- que he realizado.

Es usual que, debido a la ficción -ya sea escrita y/o audiovisual- y a los medios de comunicación, el público en general tenga una visión algo distorsionada de la realidad de lo que son los asesinos seriales. En primer lugar, no son "monstruos", "fieras" o "bestias", sino que son seres humanos como el lector o como yo; pero cuando uno de ellos emerge a la luz social resulta muy difícil de comprender su accionar por lo descarriado, cruel y/o perverso y se tiende a deshumanizarlo, como un modo de "separarse" de dichos sujetos. Lamentablemente, no es así y es frecuente -aunque hay excepciones- que estos asesinos despiadados sean nuestros vecinos, amigos, compañeros o colegas y hasta miembros de nuestra propia familia. Y, por supuesto, esta apreciación se encuentra en relación directa con la psicopatía violenta y agresiva: sujetos con una "fachada" de normalidad muy bien construida, que llevan "otra" vida oculta que tortura, ultraja $\mathrm{y}$ asesina fuera de la vista de su entorno, dejando en claro, desde este momento, que no todos los psicópatas son asesinos ni viceversa.

En la historia criminal también encontraremos a quienes son clasificados como asesinos seriales, pero fueron -o son- sujetos con serios trastornos mentales, lo cual ha sido utilizado, continuamente, por los defensores en juicio de los asesinos psicópatas: trastorno de personalidad múltiple; de estrés postraumático; psicosis indiferenciada, entre los más nombrados. Desgraciadamente los primeros fueron juzgados como "sanos mentalmente" y muchos de ellos fueron condenados a la pena de muerte; otros fueron encarcelados -de por vida- en prisiones de máxima seguridad, pero sin ningún tipo de tratamiento psiquiátrico lo cual, en ambos casos demuestra que la justicia deja de serlo para transformarse en pura y simple venganza por desconocimiento y/o rechazo, desde tiempos muy remotos, hacia las personas que sufren trastornos mentales sean agresivos o no. Pero esta actitud también tiene una contracara: los comprobados abusos del pasado con los enfermos mentales se ha transformado, bajo el lema de "la no internación involuntaria", en un arma de doble filo. Y para ello voy a dar un ejemplo: existe en la actualidad una sobrepoblación carcelaria alarmante, pero a su vez, cada vez son menos los institutos -penitenciarios o no- que albergan a personas que sufren trastornos mentales y que les brindan un tratamiento acorde a su enfermedad. Estoy totalmente de acuerdo -y no podría ser de otro modo- con la no estigmatización perpetua de aquel que sufrió o sufre un trastorno mental agudo o crónico; nadie está libre de tener un 
quiebre mental agudo o un problema psicológico en algún momento de su vida. Pero es muy distinto descargar en la familia -y, a veces, dejar librado a su suerte- a un enfermo con sus facultades mentales alteradas y con agresividad manifiesta, pues son inmanejables por su entorno, porque estas personas no pueden admitir que están enfermos y se reh úsan seguir tratamientos. Se verán varios casos de personas que, ante determinados hechos agresivos contra otros y/o sí mismos, que son "estabilizados" en un breve lapso y puestos bajo control familiar con consecuencias nefastas para ellos, su familia y la sociedad. Pero este es un problema más frecuente en las dos primeras tipologías de asesinos múltiples, los de masas e itinerantes, tal como fuera visto y explicado.

En segundo lugar, también me he propuesto "desmitificar" algunos conceptos que se encuentran fuertemente arraigados en la sociedad en general y en parte de la literatura especializada como, por ejemplo, que los asesinos seriales no son un "fenómeno norteamericano"; tampoco "exclusivamente moderno", y que el accionar criminal serial no es llevado a cabo sólo por hombres -aunque constituyen una mayoría importante- ni tampoco en forma individual.

Como adelantara, este tipo de asesinos estuvieron en nuestra sociedad desde tiempos muy remotos y precisamente, la serialidad criminal premoderna surgió en la Europa del siglo $\mathrm{XV}$. A mayor abundamiento, si se considera a los peores asesinos en serie de la historia mundial, teniendo en cuenta solamente su número de víctimas, los tres primeros "puestos" de esta lista son ocupados por criminales colombianos (Luis Garavito, Daniel Camargo Barboza y Pedro A. López) y el cuarto, por un ucraniano (Andrei Chikatilo); desgraciadamente, los cuatro fueron asesinos de niños/as, salvo el último que tuvo algunas víctimas mayores "de oportunidad".

Además, existe escasa literatura sobre asesinas seriales, que si bien constituyen una minoría, tienen un accionar criminal muy especial y, a veces, mucho más despiadado que los hombres, pues asesinan dentro de su entorno familiar y/o cercano.

Existen dos principios que son mundialmente aceptados: el primero es que quien lleva a cabo asesinatos seriales no siempre es juzgado por la totalidad de sus crímenes, sino por los que, efectivamente, pueden ser probados con certeza en sus juicios, y el segundo es que poseen más víctimas de las que admiten y/o se les pueden adjudicar de forma indubitable. De acuerdo a ambos conceptos, y teniendo en cuenta las particularidades que se brindarán cada reseña y el criterio de la cantidad de víctimas, estoy en condiciones de afirmar que el "peor asesino en serie de la historia", no es hombre ni norteamericano ni tampoco moderno: es una mujer, la condesa húngara Erzsébeth Báthory en el siglo XVII, con un estimativo de 600 víctimas, por la cantidad de restos óseos y ropas hallados en las excavaciones de los alrededores de sus dominios que no pudieron identificarse por obvias razones.

Otro concepto que por lo general no se tiene en cuenta en el estudio de la serialidad criminal es que, si bien, la norma es el accionar criminal individual, existen otras formas en que este fenómeno se manifiesta, y no por ello menos importantes. Me refiero a los casos de parejas asesinas (couples in crime o couples who kill) homo u heterosexuales unidas por un sentimiento -amor, amistad o familiar- profundo; "socios" (partners in crime) que comparten el mismo placer por el asesinato o lo hacen por codicia, y los grupos (ring murderers) donde más de dos personas se unen, por el motivo que fuera, para llevar a cabo asesinatos seriales con una cierta organización, lo que incluye familias o "clanes" enteros.

Generalmente siempre es uno de ellos el que es incluido en la categoría de asesino serial, pero si de tipificación se trata lo importante es saber qué grado de participación tuvo cada uno de ellos en los homicidios. Se verán casos que asombrarán al lector, pues es un tema relacionado en forma directa con la psicodinamia serial desde el punto de vista del asesino.

Creo que en estas palabras previas puede apreciarse la complejidad que posee el estudio del asesinato serial y debe enfocarse desde varias perspectivas; de lo cual se infiere claramente el motivo por el cual el presente volumen ha sido dividido en dos partes con el fin de abarcar lo más posible, y con la seriedad que se merece esta problemática criminal.

Como primera aproximación he procedido a hacer un estudio e investigación al dividir los diversos componentes de este fenómeno: sus generalidades, diferencias y comparaciones con otros asesinatos múltiples; las clasificaciones 
más clásicas; las variables y estereotipos que se presentan en los casos; el tema de la perfilación criminal, para culminar el presente con la primera parte de los perfiles victimológicos más "especiales" a los que se ciñen los asesinos seriales.

Las reseñas han sido ubicadas de manera tal que el lector pueda comprender y ver por sí mismo que lo elaborado en cada capítulo se ha visto materializado en la vida real. Algunos casos son tratados desde la propia historia del sujeto y su desarrollo posterior, mientras que otras comienzan exactamente como han sucedido en la realidad: personas de ambos sexos y de todas las edades que "desaparecen" o aparecen muertas, a veces en circunstancias muy especiales, y que luego de cierto tiempo se descubre que hay un vínculo entre esos hechos. Lamentablemente, cuánto más largo fue ese período, más víctimas ha habido.

Asimismo he confeccionado un Anexo en el cual se puede percibir claramente, por período de actividad, casi todos los asesinos seriales que han pasado a la historia como tales con su correspondiente ubicación geográfica.

Quiero dejar en claro desde este mismo momento, que la segunda parte se encuentra totalmente diagramada y con todo el material dispuesto, por lo que su edición se encuentra prevista para dentro de unos tres/cuatro meses, teniendo en cuenta los tiempos del diseño, la impresión y otras cuestiones comerciales que no tienen que ver con el contenido del volumen.

Como es mi costumbre, respecto de los estados y ciudades de los EE. UU., sus nombres han sido colocados en idioma original, sin traducción (ciudad de Los Angeles, en vez de "Los Ángeles"), pues no me parece correcto traducir al castellano los nombres o denominaciones de las ciudades, estados o provincias en sus idiomas originales, salvo que se trate de un caso de escritura no occidental (china, japonesa, árabe, etc.). Este criterio editorial de traducción sólo es aplicado en el caso de los nombres de los países (Nueva Zelanda, Alemania, Bélgica, etc.).

En cuanto a las reseñas, al igual que en el volumen anterior, cuando el lector halle resaltado el nombre de determinado asesino dentro de un capítulo, significa que su reseña se encuentra al final del mismo, Asimismo, y al inicio de cada una, el lector hallará junto al nombre, año de nacimiento -y deceso, si ocurrió-, su alias en idioma original si es en inglés o en español; para el caso que no lo sea en ninguno de los dos -alemán, francés, italiano, ruso, etc.- estará traducido al segundo de los citados; $\mathrm{y}$, por último, he insertado alguna frase textual perteneciente al asesino a reseñar.

A medida que el lector avance en la lectura, podrá comprender el esfuerzo en la investigación que he realizado; aunque debo señalar que con algunos casos, particularmente aberrantes como son los asesinatos de niños, muchas veces tuve que detenerme por fuertes sentimientos del más variado tenor, que podían poner en peligro mi objetividad, aunque siempre se hallará, al final de cada reseña, mi opinión particular y es mi deseo que cada persona que la lea se forme la propia, con todos los elementos de investigación a los que yo pude acceder. Ojalá esto sirva para dar algo más de luz -y no precisamente la que brinda la televisión, el cine o la literatura de ficción- a este tema tan complejo como inquietante.

\section{Susana P. García Roversi}

\section{PRÓLOGO VOL. 2, 1a PARTE, DR. VICENTE GARRIDO GENOVÉS}

La doctora García Roversi nos presenta su nueva obra, Asesinos Múltiples 2. Asesinos en Serie. $1^{\underline{a}}$ parte, y nosotros la agradecemos, alborozados, por cuanto de nuevo ha logrado realizar una nueva aportación mayúscula a la Criminología escrita en español. Los lectores que se sintieron impresionados por la calidad y extensión de su obra anterior, Asesinos Múltiples 1 , no se sentirán en absoluto decepcionados, pues la investigadora argentina hace un nuevo alarde de conocimientos y claridad expositiva.

El asesino en serie captura el interés de mucha gente, y bien lo saben los medios, que encuentran en sus actuaciones un material sensacional con el cual llenar horas de programación. Y, por supuesto, el cine y la literatura han prestado desde siempre una atención especial al relato de crímenes espectaculares y biografías de homicidas fuera de lo común, categoría donde los serial killers encajan a la perfección. La autora explica muy bien en su obra que esa fascinación es intemporal, y nos recuerda que las leyendas de hombres-lobo, vampiros y otros seres fantásticos tienen probablemente su nacimiento en esos 
depredadores humanos, cuyas huellas fueron ya objeto del interés popular a través de las historias orales transmitidas por los relatores itinerantes. Un mero repaso a las series de televisión más exitosas basta para comprobar cómo la figura del psicópata asesino en serie - Hannibal, Dexter, True Detective-sigue nutriendo de pesadillas las horas de ocio del espectador actual.

Como en el libro anterior, García Roversi nos abruma con su magnífica documentación y su erudición sobre el fenómeno del crimen en esta expresión serial. Para ello se sirve de fuentes originales, contrasta la información y nos ofrece su valoración crítica sobre los casos analizados.

Con esto quiero decir que no se ha limitado a elaborar una enciclopedia del asesinato serial, una mera lista o catálogo de asesinos o actos cometidos por éstos, sino que sitúa cada autor en su contexto social y explica sus motivaciones en el desarrollo de su biografía.

Por otra parte, la distribución de los capítulos, donde intersecciona diferentes tipos de asesinos con los perfiles criminales y victimológicos, es también un hallazgo que ofrece una perspectiva muy interesante para comprender mejor el contenido.
El libro es, como antes mencionamos, la primera parte de una obra que, magnífica y fecunda, se añade con gozo a nuestra biblioteca, pues nunca antes en la Criminología hispana se había ofrecido un trabajo tan riguroso sobre este tipo de homicidios, obra que sin duda será muy valiosa no sólo a los estudiantes de las Ciencias Sociales, sino a periodistas y escritores que tengan deseos de bucear en estas sombras oscuras para elaborar sus artículos y trabajos. Como toda obra monumental, no está pensada para ser leída "de un tirón", sino para consultarla con detenimiento y reposo, algo que además propicia la propia naturaleza del tema, pues son muchos los horrores que se refieren aquí. Pero así es este tema: horror y fascinación se mezclan a partes iguales.

En un texto científico, este atractivo está al servicio de la comprensión y el análisis, lo que distingue esta obra de la doctora García Roversi, a quien agradecemos además su pluma fácil y su interés encomiable por estudiar este fenómeno que tanto nos recuerda lo lejos que estamos de comprender cabalmente al ser humano.

Vicente Garrido Genovés 
